\title{
Correspondence
}

Editor: Ian Pullen

Contents: Inside Ciba-Geigy/Manufacture of multiple personality disorder/Sertraline in the prevention of depression/Reports of the death of factor analysis are greatly exaggerated/Maternal viral infection and schizophrenia/Influenza and schizophrenia in Japan/Schizophrenia following prenatal exposure to influenza epidemics between 1939 and 1960/Declining incidence of hysteria/Anorexia nervosa and $\mathrm{XY}$ gonadal dysgenesis/Propofol and ECT/Ventricular size in schizophrenia/Hemisphere dysfunction in psychiatric disorders/The first psychiatric use of lithium/Women and scientific thought/Hypertrichosis in mentally ill women/ Descriptions of psychiatric conditions in literature/ 'Taking Liberties'/Neuroleptic-induced dislocation of the jaw/Organic mood syndrome in two siblings with Wolfram syndrome/Psychosis, epileptiform abnormalities and clozapine/Catatonia and creatinine phosphokinase.

\section{Inside Ciba-Geigy}

SIR: Dr Birley's review (this issue, p. 286) of this book, published three years ago, focuses on a significant part of Ciba-Geigy's history and highlights the importance of total commitment to the needs of patients. The matters described in the book are of historical interest only, for as Andrew Chetley (1990) writes:

"Ciba had established several measures to help manage potential or emerging product issues, including the Medical Product Committee (which monitors and constantly reassesses the safety of marketed products), the Product Information Policy and Product Communications Audit (which codifies and controls all drug information), and the Product Issue Management and Early Warning Systems (which addresses drug issues from a pharmapolitical perspective). Nonetheless, the Company wanted to do more about drug safety and at the end of 1986, Ciba began developing an ambitious programme on the Risk Assessment of Drugs - Analysis and Response (RADAR) whose aims were to improve understanding of the various factors involved in assessing drug risk in today's complex society and to ensure that the Company's methods of informing about and promoting its drugs did not contribute to that risk".
Ciba-Geigy is committed to accepting its social responsibilities and to communication with consumers and others with legitimate interests in its business. We welcome constructive criticism from bodies such as MALAM. Constructive criticism is a vital part of innovation and these interactions help Ciba-Geigy to be a world leader in scientific knowledge and ethical practice, both key to our present and future business success.

Chetley, A. (1990) "A Healthy Business" World Health and the Pharmaceutical Industry. London and New Jersey: Zed Books Lid.

\section{Ciba-Geigy Pharmaceuticals Wimblehurst Road}

Horsham

West Sussex RH12 4AB

\section{Manufacture of multiple personality disorder}

SIR: I am angered by Merskey's article (Journal, March 1992, 160, 327-340), just as I was by Fahy's review on the same subject (Journal, September 1988, 153, 597-606). I did my psychiatric training in Galway in the early 1980 s and immigrated to Canada in 1986. At that time I was also very sceptical of the diagnosis of multiple personality disorder (MPD) but that has changed in my last six years of practice; through diagnosing and treating people with MPD and other sequelae of sexual abuse, and attending conferences on the subject, I now have no doubts that such an illness exists.

I do not use hypnosis in diagnosing or treating this or any other condition, nor would I even think of suggesting this diagnosis at the initial interviews. I have found that patients are so ashamed of their symptoms, of their feelings, of hearing voices in their head, of their loss of memory and of feeling that they are a freak or are going crazy, that they think I will not continue to treat them if they disclose these feelings or symptoms. I have found that patients are often in treatment for many months to years, testing and learning to trust me before they are willing to 
share their secrets and the diagnosis of MPD is made. In my opinion it is not the diagnosis that we treat but the patient as a whole. The diagnosis should not change our method of treatment as the treatment of choice is in-depth psychotherapy to explore the abusive background, thus helping the patients to free themselves and take control of their own lives.

I note with interest that this article has been written by a psychiatrist from Ontario. I can only surmise that he felt this article would be more acceptable to the British than to the North American psychiatrist.

\section{Broad Street \\ Brockville \\ Ontario K6V $4 T 8$}

MAEVE FAHY

SIR: Merskey writes about the production of multiple personality disorder (Journal, March 1992, 160, 327-340). As a fellow Canadian psychiatrist I feel compelled to write and advocate an entirely contrary position; one that is shared by the majority of psychiatrists of my personal experience. Writing this letter is especially important as it is my impression, based on contacts with British colleagues, that they are not yet totally familiar with MPD. There may be a large population with MPD in Britain, unrecognised and untreated. The bias of the articles that appear in the Journal about MPD would seem to support this.

My first acquaintance with a patient subsequently diagnosed as MPD was during my first days as a psychiatrist resident on a long-term rehabilitation unit. There was absolutely no experience on this unit, either by the consultant psychiatrist or the staff, with the diagnosis. During my undergraduate medical training (in Britain in the 1960s) MPD had never been mentioned. Neither the patient nor myself had seen the movie Eve or read Sybil. I had four months of accumulating historical data and clinical observations that did not fit the many psychiatric diagnoses that had been made before I started learning about dissociative disorders.

I found my patient totally consistent with the descriptions appearing in the literature, and continued to parallel descriptions in the writings and workshops that have blossomed over the past six years. How could I have induced a 'classical case' when I had absolutely no notion of what that might mean? I believe Dr Merskey is correct when he writes "MPD offers a mode of separating, splitting and isolating particular subjective problems", but I believe that the aetiology is in the horrific childhood experiences of these patients, not in response to suggestions by a therapist. The extensive clinical experience with MPD in childhood supports this.

I cannot follow the logic of the argument that to diagnose MPD may hinder the most appropriate treatment. Surely accurate diagnosis in any illness has always been the first step in management? MPD is a treatable condition with an optimistic prognosis if recognised and managed appropriately. The emphasis should be on better preparing psychiatrists to be familiar with treatment options.

Dr Merskey may fear that he may be so "distracted" by the "exciting" diagnosis that he will forget basic principles of biopsychosocial management and neglect to treat coexisting conditions. It is not my experience that those of us who are comfortable with working with MPD patients do this. We do indeed treat the 'whole' patient.

PO Box 974

Ann Chande

Morrisburg

Ontario

Canada KOC $1 X O$

AUTHOR'S REPLY: Dr Chande indicates that the majority of Canadian psychiatrists of her acquaintance accept the concept of multiple personality disorder (MPD). My experience differs and extends to Canadian, British, United States and Australasian psychiatrists, and the majority with whom I have discussed the issue are sceptical of the validity of the disorder. Orne \& Bauer-Manley (1991) observe polarisation between " . . a relatively small group of therapists ... reporting large numbers of cases (increasingly with large numbers of 'personalities' in each case) and others who believe that if MPD occurs spontaneously at all, it does so extremely rarely". We do not know the proportions of support for this diagnosis at the present time, but it is controversial, a point made in the discussion of it in ICD-10. I accept that Dr Chande did not induce her "classical case", but the risk of her patient being influenced by the media is not limited to seeing the two films in question, and prior contacts may also have been relevant.

The diagnosis of MPD is not always a distraction from treating other conditions. However, in practice that is how Chodoff (1987) has observed it to work and that is the observation of myself and colleagues in four cases which we have prepared for publication. These are the first four alleged cases that we have seen to date. Their treatment was not helped by a diagnosis of MPD, and their management would have been better if the basic principles of biopsychosocial management had been employed in their cases. 